\title{
Características biométricas de sementes crioulas de Crotalaria e Milheto
}

\author{
Shirley Santos Monteiro ${ }^{1}$, Dualyson da Silva Santos ${ }^{1}$, Juliana Ferreira de Lima ${ }^{1}$, Shênia Santos Monteiro ${ }^{2}$ \\ ${ }^{1}$ Universidade Estadual da Paraíba; shirley_pinto_monteiro@ hotmail.com; dualyson @gmail.com; \\ julianacavnufpb@ hotmail.com; ${ }^{2}$ Universidade Federal de Campina Grande; shenia-monteiro @ gmail.com.
}

\begin{abstract}
RESUMO: A germinação de sementes é base para a propagação de espécies nativas para o entendimento da regeneração natural em comunidades vegetais. O objetivou-se com este estudo determinar as características biométrica de sementes crioulas de Crotalaria e Milheto. O experimento foi conduzido na Universidade Federal da Paraíba, Bananeiras-PB. Utilizou-se sementes de Crotalaria spectabelis, Crotalaria juncea e Pennisetum glaucum, adquiridas dos agricultores familiares local. $\mathrm{O}$ delineamento utilizado foi inteiramente casualizado, com 4 repetições de 50 sementes. Avaliou-se o índice de velocidade de germinação, germinação, comprimento da raiz principal, hipocótilo e epicótilo, e determinação da massa fresca e seca das plântulas estudadas. Os resultados demostram a eficiência do teste de germinação para o potencial germinativo e viabilidade das sementes. As Crotalaria spectabelis e juncea demostraram qualidade fisiológica de sementes superior ao Pennisetum glaucum, o que concerne aos parâmetros de germinação e vigor.
\end{abstract}

PALAVRAS-CHAVE: Brejo Paraibano; Germinação; Propagação de sementes; Viabilidade de sementes.

\section{INTRODUÇÃO}

A germinação é um fenômeno fisiológico que se inicia com a entrada de água na semente e termina com o início do alongamento do eixo embrionário, a radícula (SOUSA-SILVA et al., 2001). Este processo representa uma fase crítica do ciclo de vida das espécies vegetais e os fatores que a afetam, como temperatura, tipo de substrato, umidade e luminosidade, são relevantes tanto em termos tecnológicos quanto ecológicos. Os fatores interferem diretamente na porcentagem de sementes germinadas e na velocidade com que este processo ocorre. Portanto, a análise da germinação de sementes é base para a propagação de espécies nativa se para o entendimento da regeneração natural em comunidades vegetais (COSMO et al., 2017).

A água é o fator iniciante da germinação e está envolvida direta e indiretamente em todas as demais etapas do metabolismo germinativo. Sua participação é decisiva nas reações enzimáticas, na solubilização e transporte de metabólitos, também como reagente na digestão hidrolítica de tecidos de reserva da semente. Assim, potenciais osmóticos muito negativos inibem o potencial de germinação da grande maioria das culturas cultivadas (KRON et al., 2008).

A semente é vida, base de alimento, multiplicação, crescimento, sobrevivência, é o elemento básico da agricultura como estratégia social. Na vida camponesa a posse das sementes próprias representa autonomia, liberdade, poder popular, independência e autossuficiência (GUTIÉRREZ, 2003). A realidade tem mostrado que os pequenos agricultores têm realizado um papel que vai além da agricultura (MONTEIRO et al., 2018).

As espécies de crotalarias apresentam elevada capacidade de produção de biomassa, fixação de nitrogênio e redução do número plantas daninhas (TEODORO et al., 2011; ARAÚJO et al., 2015). A Crotalaria juncea L. e Crotalaria spectabelis $\mathrm{L}$. possuem alto potencial de produção de biomassa e sua utilização como adubo verde pode promover melhorias nos atributos químicos, físicos e biológicos do solo, tornando-a uma importante opção na recuperação de áreas degradadas (NUNES et al., 2009).

O milheto é o sexto cereal mais consumido no planeta (DURÃES et al., 2003). O Pennisetum glaucum L. apresenta resistência a seca, boa produção de biomassa, crescimento rápido, boa adaptação em diferentes níveis de fertilidade, resistência as pragas e doenças, facilidade de produção de sementes e forragem de qualidade, esta cultura tem-se apresentado como uma das melhores opções para a cobertura do solo em áreas de semeadura direta no Brasil (BERGAMASCHINE et al., 2011; DOMUKOSKI et al., 2014).

Baseando-se em uma perspectiva agroecológica o uso de variedades crioulas é um fator condicionante para um manejo dos agroecossistemas saudáveis e sustentáveis, pois essa estratégia viabiliza o emprego de genótipos localmente adaptados, que são capazes de converter recursos abióticos disponíveis nos agroecossistemas em biomassa de interesse econômico (PETERSEN et al., 2013; MONTEIRO et al., 2018).

A produção das sementes de leguminosas e gramíneas adaptadas as características de semiáridos vem sendo multiplicadas e divulgadas após de ter chegado quase a sua extinção com o surgimento das sementes geneticamente modificadas. O objetivou-se com este estudo determinar as características biométrica de sementes crioulas de Crotalaria e Milheto. 
MONTEIRO, S. S. et al. Características biométricas de sementes crioulas de Crotalaria e Milheto. In: II Congresso Paraibano de Agroecologia \& IV Exposição Tecnológica, 2019. Anais... Caderno Verde de Agroecologia e Desenvolvimento Sustentável, Pombal, v. 9, n.7, e-6878, 2019.

\section{MATERIAL E MÉTODOS}

O experimento foi conduzido no ano de 2016 no Laboratório de Tecnologia de Sementes do Centro de Ciências Humanas, Sociais e Agrárias (CCHSA) da Universidade Federal da Paraíba (UFPB), Bananeiras-PB. Utilizou-se sementes de Crotalaria spectabelis, Crotalaria juncea e Pennisetum glaucum, adquiridas dos agricultores familiares do município de Bananeiras-PB.

As avaliações da morfologia, da germinação e da plântula, foram conduzidas em quatro repetições de 10 (dez) sementes, semeadas em caixas de plástico tipo gerbox, forradas internamente com duas folhas de papel gemiteste autoclavado e umedecida com três vezes o peso do papel. As caixas gerbox foram colocadas em incubadora BOD, a 20 ${ }^{\circ} \mathrm{C}$.

Para o cálculo do índice de velocidade de germinação (IVG) foram realizadas contagens diárias das sementes que apresentaram raiz primária. Foram amostradas 10 (dez) plântulas para as avaliações individuais de comprimento da raiz principal, hipocótilo e epicótilo, utilizando-se um paquímetro digital, com precisão de 0,01 mm. Essas plântulas foram submetidas à secagem a $60^{\circ} \mathrm{C}$ por 72 horas em estufa com circulação de ar e determinados os valores da matéria seca.

Foi utilizado um delineamento experimental inteiramente casualizado, com quatro repetições de 50 sementes. Os dados foram submetidos a análise de variância, as médias foram comparadas pelo teste T, a 5\% de significância, pelo Programa estatístico SAS.

\section{RESULTADOS E DISCUSSÃO}

Os dados da ANOVA mostram, que houve diferença significativa para o índice de velocidade de germinação (IVG), germinação e massa seca de raiz primária (Tabela 1). Ao relacionar as sementes germinadas neste estudo, observou-se que as sementes de Crotalaria spectabelis e juncea apresentaram percentagem de IVG e germinativa superiores e uniforme ao ser relacionado com Pennisetum glaucum.

Tabela 1. Resumo da análise de variância dos atributos avaliados na germinação de sementes de Crotalaria spectabelis, Crotalaria juncea e Pennisetum glaucum.

\begin{tabular}{lcccccccc}
\hline & IVG & G & RP & H & MFRP & MFH & MSRP & MSH \\
\hline QM & $360,025^{*}$ & $458,085^{*}$ & $6,502^{\mathrm{ns}}$ & $1,145^{\mathrm{ns}}$ & $0,911^{\mathrm{ns}}$ & $6,515^{\mathrm{ns}}$ & $0,294^{*}$ & $1,280^{\mathrm{ns}}$ \\
DP & 45,67 & 85,81 & 6,21 & 3,13 & 1,89 & 5,79 & 0,76 & 1,85 \\
CV $(\%)$ & 7,58 & 3,51 & 27,33 & 21,72 & 33,53 & 29,68 & 30,36 & 64,61 \\
\hline
\end{tabular}

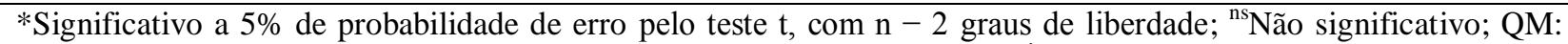
Quadrado médio; DP: Desvio padrão; CV: Coeficiente de variação; IVG: Índice de velocidade de germinação; G: Germinação; RP: Raiz Primária; H: Hipocótilo; MFRP: Massa fresca de raiz primária; MFH: Massa fresca de hipocótilo; MSRP: Massa seca raiz primária; MSH: Massa seca de hipocótilo.

Não houve diferença estatística significativa para os valores de raiz primária, hipocótilo, massa fresca da raiz primária e hipocótilo e massa seca de hipocótilo (Tabela 1). Sendo assim, não é aconselhável utilizar esse parâmetro morfológico como caráter taxonômico para a diferenciação dessas três espécies, visto que suas medidas são bastante similares (BEZERRA et al., 2018).

De acordo com Silva et al. (2017) o comprimento da raiz primária é inibido pelo aumento do volume de água no substrato nas diferentes temperaturas ao qual for submetida as sementes. Kerbauy (2008) afirme que a diminuição na absorção de água pelas sementes pode ser caracterizada por menos comprimentos de plântulas e menor acúmulo de matéria seca. De acordo com Azevedo Neto et al. (2004), ao estudarem o crescimento e desenvolvimento de diferentes genótipos de milho, não observaram diferença significativa entre os genótipos testados.

De acordo com os dados obtidos, a Crotalaria spectabelis e juncea apresentaram diferença em relação a Pennisetum glaucum o que diferem estatisticamente entre si (Figura 1). As Crotalaria spectabelis e juncea apresentaram o melhor desempenho no índice de velocidade de germinação, visto que obtiveram a maior porcentagem de plântulas normais. Estudos apontam que cultivares com porcentagem de índice de velocidade de germinação semelhante, frequentemente possuem diferença (MARCARELLO et al., 2012), mostrando assim que as espécies de crotalaria tiveram o mesmo comportamento.

O percentual germinativo da Crotalaria spectabelis e juncea atingiram seu máximo em relação ao Pennisetum glaucum (Figura 1). Durante o desenvolvimento, as sementes adquirem a capacidade de tolerar a dessecação e, dessa forma, reduzem a atividade metabólica, o que aumentar sua longevidade, além de conferir a tolerância as condições ambientais extremas (LEPRINCE; BUITINK, 2010). Já o Pennisetum glaucum apresentou decréscimo no potencial de germinação (Figura 1), o qual pode ter ocorrido devido a absorção de sais mais solúveis, os quais são nocivos e podem causar efeitos tóxicos ou mais limitantes, uma vez que as sementes ao absorverem a água, também absorve íons que, conforme as concentrações, podem causar toxidez e ocasionar distúrbios fisiológicos e decréscimo no potencial de germinação (LIMA et al., 2001). 
MONTEIRO, S. S. et al. Características biométricas de sementes crioulas de Crotalaria e Milheto. In: II Congresso Paraibano de Agroecologia \& IV Exposição Tecnológica, 2019. Anais... Caderno Verde de Agroecologia e Desenvolvimento Sustentável, Pombal, v. 9, n.7, e-6878, 2019.

Figura 1. Porcentagem de índice de velocidade de germinação e germinação de sementes de Crotalaria spectabelis, Crotalaria juncea e Pennisetum glaucum

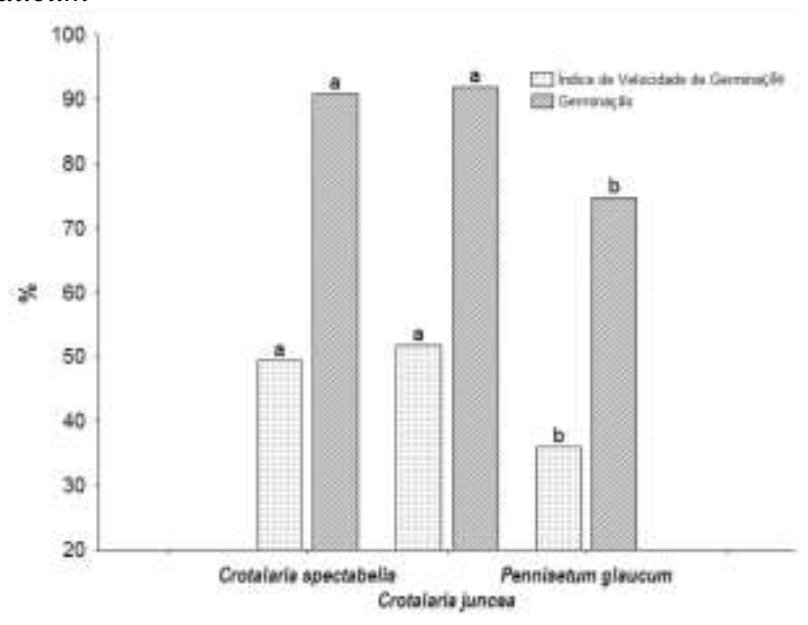

Figura 2. Massa fresca e seca da raiz primária e hipocótilo de sementes de Crotalaria spectabelis, Crotalaria juncea e Pennisetum glaucum

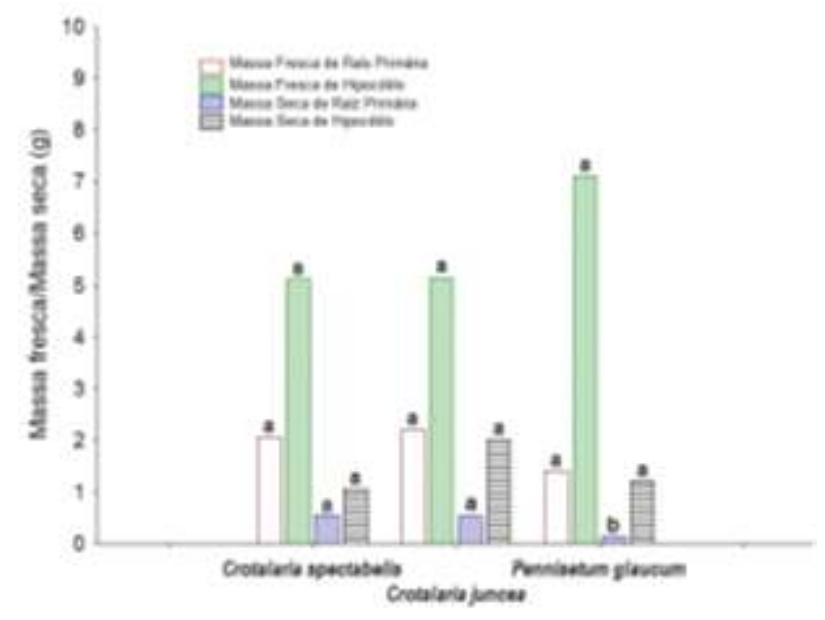

Dessa forma, para o estudo de massa fresca de Crotalaria spectabelis, Crotalaria juncea e Pennisetum glaucum apresentado na Figura 2, não diferiram entre si, da mesma forma quanto a massa seca de hipocótilos, confirmando que as sementes apresentam um comportamento semelhante entre si, e que as condições as quais foram submetidas ao processo germinativo das sementes não afetou.

Os dados coletados de massa seca de raiz primária apresentaram diferença significativa entre as sementes estudadas (Tabela 1), indicando que as plântulas de Crotalaria spectabelis e juncea expressaram comportamento diferente do Pennisetum glaucum. Este fato pode ser atribuído fatores intrínsecos das sementes com uma menor quantidade de substâncias de reserva, que provavelmente, foram consumidas durante o processo vital de germinação ao longo do tempo de armazenamento das sementes (SILVA et al., 2015).

A biometria destas espécies são importantes ferramentas para descrever as características morfológicas, identificando de forma única cada indivíduo, presentes numa mesma área, assim como identificar variações existentes entre espécies de mesmo género, através de caracterização morfológica e de adaptação de indivíduos (MATHEUS; LOPES, 2007; GONÇALVES et al., 2013; GOMES et al., 2016; SANTOS et al., 2016; SANTOS et al., 2018). As análises biométricas são consideradas, como ponto de partida para a classificação das sementes, estratégia que pode ser adotada para uniformizar a emergência das plântulas e maior vigor (CARVALHO; NAKAGAWA, 2000).

\section{CONCLUSÕES}

A Crotalaria spectabelis e juncea demostrou qualidade fisiológica de sementes superior ao Pennisetum glaucum, o que concerne aos parâmetros de germinação e vigor. 
MONTEIRO, S. S. et al. Características biométricas de sementes crioulas de Crotalaria e Milheto. In: II Congresso Paraibano de Agroecologia \& IV Exposição Tecnológica, 2019. Anais... Caderno Verde de Agroecologia e Desenvolvimento Sustentável, Pombal, v. 9, n.7, e-6878, 2019.

\section{REFERÊNCIAS}

ARAÚJO, L. S.; CUNHA, P. C. R.; SILVEIRA, P. M.; SOUSA NETTO, M.; OLIVEIRA, F. C. Potencial de cobertura do solo e supressão de tiririca (Cyperus rotundus) por resíduos culturais de plantas de cobertura. Revista Ceres, ViçosaMG, v. 62, p. 483-488, 2015.

AZEVEDO NETO, A. D.; PRISCO, J. T.; ENÉAS FILHO, J.; LACERDA, C. F.; SILVA, J. V.; COSTA, P. H. A.; GOMES FILHO, E. Effects of salt stress on plant growth, stomatal response and solute accumulation of diferente maize genotypes. Brazilian Journal of Plant Physiology, Campos dos Goytacazes-RJ, v. 16, n. 1, p. 31-38, 2004.

BERGAMASCHINE, A. F.; FREITAS, R. V. L.; VALÉRIO FILHO, W. V. Substituição do milho e farelo de algodão pelo milheto no concentrado da dieta de novilhos em confinamento. Revista Brasileira de Zootecnia, Viçosa-MG, v. 40, n. 1, p. 154-9, 2011.

BEZERRA, J. W. A.; SIlVA, M. A. P.; BATISTA, A. P.; MENDONÇA, A. C. A. M.; SOUSA, J. F. O.; SANTOS, M. A. F.; SILVA, V. B. Biometria e quebra de dormência em Dimorphandra gardneriana Tul. (Faveira) (Fabaceae). Revista Cubana de Plantas Medicinales, Espanha, v. 23, n. 4, p. 2018.

CARVALHO, N. M.; NAKAGAWA, J. Sementes: ciências, tecnologia e produção. Jaboticabal: FUNEP, JaboticabalSP. 588p. 2000.

COSMO, N. L.; GOGOSZ, A. M.; REGO, S. S.; NOGUEIRA, A. C.; KUNIYOSHI, Y. S. Morfologia de fruto, semente e plântula, e germinação de sementes de Myrceugenia Euosma (O. BERG) D. Legrand (Myrtaceae). Floresta, CuritibaPR, v. 47, n. 4, p. 479-488, 2017.

DURÃES, F. O. M.; MAGALHÃES, P. C.; SANTOS, F. G. Fisiologia da planta de milheto. Sete Lagoas: Embrapa CNPMS, Circular Técnica - 28, Sete Lagoas-MG, p.13, 2003.

DOMUKOSKI, J. F.; COSTA, A. C. T.; LÁZARO, R. L. Produção de biomassa do milheto em função do espaçamento entrelinhas e da densidade de semeadura. Scientia Agraria Paranaensis, Marechal Cândido Rondon-PR, v. 13, n. 2, p. 152-60, 2014.

GONÇALVES, L. G. V.; ANDRADE, F. R.; MARIMON JUNIOR, E. H.; SCHOSSLER, T. R.; MARIMON, B. S. Biometria de frutos e sementes de mangaba (Hancornia speciosa Gomes) em vegetação natural na região leste de Mato Grosso, Brasil. Revista de Ciências Agrárias, Dois Irmãos-PE, v. 36, n. 1, p. 31-40, 2013.

GOMES, D. R.; ARAÚJO, M. M.; NUNES, U. R.; AIMI, S. C. Biometry and germination of Balfourodendron riedelianum Eng. Journal of Seed Science, Londrina-PR, v. 38, n. 3, p. 187-194, 2016.

GUTIÉRREZ, M. M. Sementes crioulas: um olhar a partir da colômbia. In CARVALHO, H. M. de, (ORG) Sementes: patrimônio do povo a serviço da humanidade. $1^{\text {a }}$ Ed. São Paulo-SP: Expressão Popular, São Paulo-SP, p. 261-277, 2003.

LIMA, K. L.; CAVALCANTE, L. F.; FEITOSA FILHO, J. C. Efeitos de fontes e níveis de salinidade da água de irrigação sobre a germinação e o crescimento da pinheira. Engenharia Agrícola, Jaboticabal-SP, v. 21, n. 2, p. 135-144, 2001.

LEPRINCE, O.; BUITINK, J. Desiccation tolerance: From genomics to the field. Plant Science, Sitges, Espanha. v. 179 , n. 6, p. 554-564, 2010.

KRON, A. P.; SOUZA, G. M.; RIBEIRO, R. V. Water deficiency at different developmental stages of Glycine max can improve drought tolerance. Bragantia, Campinas-SP, v. 67, n. 1, p. 43-49, 2008.

KERBAUY, G. B. Fisiologia vegetal. Rio de Janeiro: Guanabara Koogan, Rio de Janeiro, 452 p., 2008.

MATHEUS, M. T.; LOPES, J. C. Morfologia de frutos, sementes e plântulas e germinação de sementes de Erythrina variegata L. Journal of Seed Science, Londrina-PR, v. 29, n. 3, p. 8-17, 2007.

MARCARELlo, A.; YAMASHITA, O. M.; CARVALHO, M. A. C. Qualidade fisiológica de sementes de feijoeiro em função da aplicação foliar de cobalto e molibdênio. Global Science Technology, Rio Verde-GO, v. 5, n. 2, p. 121-132, 2012. 
MONTEIRO, S. S. et al. Características biométricas de sementes crioulas de Crotalaria e Milheto. In: II Congresso Paraibano de Agroecologia \& IV Exposição Tecnológica, 2019. Anais... Caderno Verde de Agroecologia e Desenvolvimento Sustentável, Pombal, v. 9, n.7, e-6878, 2019.

MONTEIRO, S. S.; SANTOS, D. S.; JESUS, J. C.; VASCONCELlOS, A.; LIMA, J. F.; MARINI, F. S. Produção de Canavalia ensiforme em diferentes espaçamentos no estado da Paraíba. Cadernos de Agroecologia, Brasília-DF, v. 13, n. 1, p. 1-7, 2018.

NUNES, A. S.; LOURENÇÃO, A. L. F.; PEZARICO, C. R.; SCALON, S. P. Q.; GONÇALVES, M. C. Fontes e níveis de salinidade na germinação de sementes de Crotalaria juncea L. Ciências Agrotecnologica, Lavras-MG, v. 33, n. 3, 2009.

PETERSEN, P.; SILVEIRA, L.; DIAS, E.; CURADO, F.; SANTOS, A. Sementes ou grãos? Lutas para desconstrução de uma falsa dicotomia. Agriculturas, Rio de Janeiro-RJ, v. 10, n. 1, p. 36-45, 2013.

SILVA, T. C.; ALVES, M. C. S.; TEODORO, M. S.; LACERDA, M. N. Avaliação e potencial fisiológico de sementes de Crotalaria juncea L em três períodos diferentes de armazenamento. Enciclopédia Biosfera, Goiânia-GO, v. 11, n. 20, p. $40-52,2015$.

SIlVA, G. M.; CRUZ, F. R. S.; ALVES, E. U.; SILVA, R. S.; ALVES, M. M.; SANTOS NETA, M. M. S.; OLIVEIRA, G. M. Umedecimento do substrato e temperatura no vigor de sementes de sabiá (Mimosa caesalpiniifolia Benth.). Anais do 20 Congresso Brasileiro de Sementes 07 a 10 de agosto de 2017 Foz do Iguaçu-PR. (Org.). Denise Cunha Fernandes dos Santos Dias et al. - Foz do Iguaçu-PR. Informativo Abrates, Foz do Iguaçu-PR, v. 27 , n. 2 , 2017.

SANTOS, J. C. C.; COSTA, R. N.; SILVA, D. M. R.; SOUZA, A. A.; MOURA, F. B. P; SILVA JUNIOR, J. M.; SILVA, J. V. Use of allometric models to estimate leaf area in Hymenaea courbaril L. Theoretical and Experimental Plant Physiology, v. 28, p. 357-369, 2016.

SANTOS, J. C. C.; SILVA, D. M. R.; COSTA, R. N.; SILVA, C. H.; SANTOS, W. S.; MOURA, F. B. P.; SILVA, J. V. Aspectos biométricos e morfológicos de frutos e sementes de Schinopsis brasiliensis. Nativa, Sinop-MT, v. 6, p. 219-224, 2018.

SOUSA-SILVA, J. C.; REBEIRO, J. F.; FONSECA, C. E. L.; ANTUNES, N. B. Germinação de sementes e emergência de plântulas de espécies arbóreas e arbustivas que ocorrem em matas de galeria. In: Ribeiro, J. F.; Fonseca, C. E. L.; Sousa-Silva, J. C. (Eds). Cerrado: caracterização e recuperação de matas de galeria. Planaltina: Embrapa Cerrados, Viçosa-MG, p. 379-422, 2001.

TEODORO, R. B.; OLIVEIRA, F. L.; SILVA, D. M. N.; FÁVERO, C.; QUARESMA, M. A. L. Aspectos agronômicos de leguminosas para adubação verde no Cerrado do Alto Vale do Jequitinhonha. Revista Brasileira de Ciência do Solo, Viçosa-MG, v. 35, p. 635-640, 2011.

\section{AGRADECIMENTOS}

Apoio financeiro: Fundação de Apoio à Pesquisa do Estado da Paraíba - FAPESQ. 